\title{
Electrical impedance cardiogram in derivation of systolic time intervals
}

\author{
V. BALASUBRAMANIAN, O. P. MATHEW, ARUN BEHL, S. C. TEWARI, \\ AND R. S. HOON \\ From The Stress Test and Noninvasive Laboratory, Army Hospital, Delhi Cantt, New Delhi 110010, India
}

SUMMARY The reliability and use of the differentiated electrical impedance cardiogram (dZ/dt) in calculating systolic time intervals were assessed in 185 subjects under varying conditions. In the first phase, simultaneous recording of carotid pulse, $\mathrm{dZ} / \mathrm{dt}$, electrocardiogram and phonocardiogram (PCG) was obtained in 50 normal volunteers under controlled conditions. In the second phase $\mathrm{dZ} / \mathrm{dt}$, electrocardiogram and phonocardiogram were obtained initially, and carotid pulses, electrocardiograms, and phonocardiograms were recorded immediately afterwards. Serial recordings were obtained in 35 subjects at sea-level, and at $3658 \mathrm{~m}$ altitude after $1,2,3,4,5$, and 10 days of induction. The subjects returned to sea-level and daily studies were carried out days 2 and 3. It was found that the impedance ventricular ejection time $\left(\mathrm{LVET}_{\mathrm{z}}\right)$ and the ventricular ejection time derived from the carotid pulse $\left(\mathrm{LVET}_{\mathrm{c}}\right)$ were within $10 \mathrm{~ms}$ of each other in all recordings and a close correlation was obtained between the two $(R=0.976)$. The impedance pre-ejection period $\left(\mathrm{PEP}_{\mathrm{z}}\right)$ obtained by direct measurement (from the onset of the $Q$ wave of the electrocardiogram to the onset of $\mathrm{dZ} / \mathrm{dt}$ wave form) also had an excellent correlation with carotid pre-ejection period $\left(\mathrm{PEP}_{c}\right)$ obtained by the formula $\mathrm{QS} 2-\mathrm{LVET}_{\mathrm{c}}(\mathrm{R}=0.91)$, where QS2 represents electromechanical systole.

In 50 subjects LVET $_{\mathrm{c}}$ and LVET $_{\mathrm{z}}$ were compared after isometric handgrip exercise. There was no significant difference between them. Thirty patients with ischaemic heart disease and 20 normal subjects participated in dynamic bicycle ergometer exercise. In this group technical difficulties prevented recording of satisfactory $\mathrm{dZ} / \mathrm{dt}$ tracings beyond 50 watts load during exercise. Tracings immediately after exercise were, however, satisfactory for analysis, and the parameters calculated yielded a good correlation with those obtained from carotid pulse recordings.

Systolic time intervals have been firmly established as reliable noninvasive indicators of myocardial function in health and disease (Weissler et al., 1968, 1969; Martin et al., 1971; Weissler et al., 1972; Balasubramanian et al., 1975a; Spodick and Lance, 1976). Conventionally they are calculated by simultaneously recording the electrocardiogram, phonocardiogram, and carotid pulse at a minimum paper speed of $100 \mathrm{~mm} / \mathrm{s}$. The electromechanical systole (QS2) is obtained by measuring the time between the onset of the QRS complex and the aortic closure, and the left ventricular ejection time is derived from the interval between the upstroke of the carotid pulse and the nadir of the dicrotic notch. Because of the inevitable pulse transmission delay, the pre-ejection period is obtained indirectly by subtracting left ventricular ejection time from QS2

Received for publication 15 July 1977
(Spodick and Lance, 1976). The derivation of left ventricular ejection time from the carotid pulse is not always easy. In obese people, in those with thick necks, and in patients who are breathing rapidly the pulse may be difficult to find. The need for a good transducer with an adequate time constant and the necessity to hold the transducer over the carotid pulse have also presented problems. These have led to the use of other pulse waveforms to calculate left ventricular ejection time. Chirife and Spodick (1972) used digital plethysmography and QuarryPigott et al. (1973) earlobe densitography for this purpose; the latter has been used during exercise because it is extremely stable. These methods, however, have the disadvantage of using peripheral pulses with a definite transmission delay necessitating the use of indirect calculation of pre-ejection period. Spodick and Lance (1976) recently discussed the possibility of eliminating the phonocardiogram 


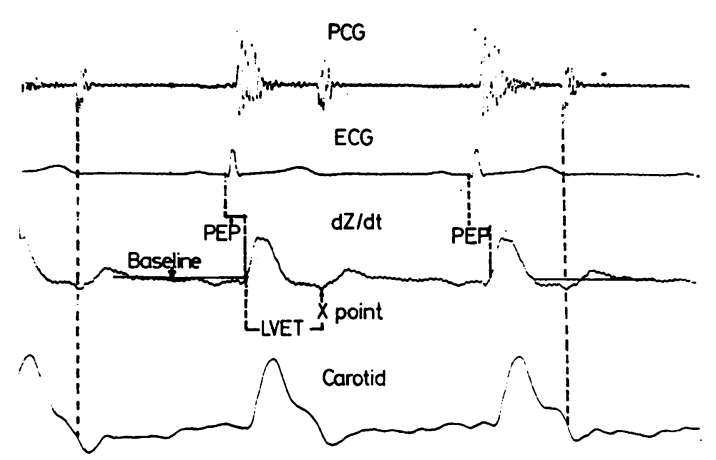

Fig. 1 Simultaneous recording of electrocardiogram, phonocardiogram, $d Z / d t$, and carotid pulse at a paper speed of $100 \mathrm{~mm} / \mathrm{s}$. The vertical interrupted line shows the earlier onset of the ' $X$ ' point of $d Z / d t$ as compared with the dicrotic notch of the carotid pulse.

during these recordings with a view to simplifying the recording procedures.

The differentiated electrical impedance cardiogram $(\mathrm{dZ} / \mathrm{dt})$ has been in regular use for over a decade to calculate stroke volume and cardiac output (Kubicek et al., 1966, 1970, 1974; Baker et al., 1971, 1974; Naggar et al., 1975; Denniston et al., 1976). As the ventricular ejection time is routinely calculated during this computation the possibility of using the impedance cardiogram for derivation of systolic time intervals seemed propitious.

\section{Subjects and methods}

The study consisted of three phases.

PHASE I

Simultaneous recordings of carotid pulse, $\mathrm{dZ} / \mathrm{dt}$, phonocardiogram, and electrocardiogram in 50 normal male healthy volunteers, with ages ranging from 20 to 35 years were studied once. All recordings were made between 0800 and 1100 hours in the postabsorptive state in the supine position. The $\mathrm{dZ} / \mathrm{dt}$, electrocardiogram, carotid pulse, and phonocardiogram were simultaneously recorded (Fig. 1). A six-channel direct writing recorder was used at a paper speed of $100 \mathrm{~mm} / \mathrm{s}$. Carotid pulse was obtained by a crystal transducer ${ }^{1}$ (APT-102) applied directly over the carotid artery and the phonocardiogram by a dynamic microphone (HM 612). ${ }^{1}$ The $\mathrm{dZ} / \mathrm{dt}$ and electrocardiogram were obtained with the tetrapolar circular lead system. Two pairs of silver-coated copper mesh strips, $5 \mathrm{~mm}$ in diameter, bonded to a nonconductive neoprene

${ }^{1}$ Kombinat Veb Messegeratewerk, GDR. belt at a distance of $5 \mathrm{~cm}$ were used as electrodes (Fig. 2). The upper pair were applied around the neck and the lower pair at the xiphisternum. A noncorrosive electrolyte cream was used to ensure good electrode to skin contact. The peripheral electrodes $\mathrm{E}_{1}$ and $\mathrm{E}_{4}$ picked up the electrocardiographic signals and also transmitted a constant sinusoidal alternating current of 200 microamperes of $20 \mathrm{KHz}$. The inner pair of electrodes $E_{2}$ and $E_{3}$ picked up the impedance changes across the thorax, which were processed by a custom-built digital impedance plethysmograph to yield the first derivative of the impedance cardiogram. A minimum of 8 to 10 complexes were recorded with breath held in comfortable end-expiration.

\section{PHASE II}

Recording dZ/dt, electrocardiogram, and phonocardiogram during end-expiration; carotid pulse, electrocardiogram, and phonocardiogram immediately afterwards in 35 normal healthy volunteers at sea-level and serially at high altitude. Their ages ranged from 20 to 35 years. The first set of recordings was obtained at sea-level. The subjects were then taken to an altitude of $3658 \mathrm{~m}$ by road in 6 hours where the studies were repeated daily for 5 consecutive days and on the tenth day. They were then brought back to sea-level and repeat studies were performed on the second and third day of return. The recording was obtained using a threechannel portable direct writing recorder, 1 with identical methods as in phase I except that the electrocardiogram, $\mathrm{dZ} / \mathrm{dt}$, and phonocardiogram were recorded initially with the subject holding his breath in comfortable end-expiration. Immediately

${ }^{1}$ Kombinat Veb Messegeratewerk, GDR.

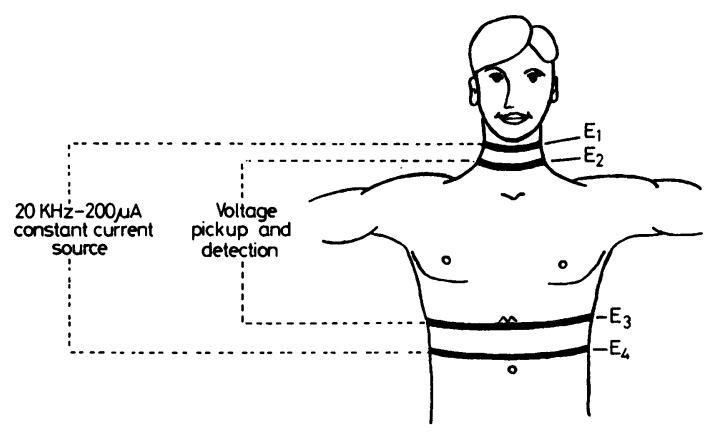

Fig. 2 Electrode locations for electrical impedance cardiography. The outer electrodes $E_{1}$ and $E_{4}$ are used to transmit the current across the thorax, and the inner electrodes $E_{2}$ and $E_{3}$ to pick up the voltage changes. The electrodes $E_{1}$ and $E_{4}$ are also used to pick up the electrocardiographic signal for timing purposes. 
afterwards the electrocardiogram, carotid tracing, and phonocardiogram were obtained with the subject breathing normally. The electrocardiogram was derived from the peripheral impedance electrodes for this study also.

\section{PHASE III}

Exploring the possibility of recording $\mathrm{dZ} / \mathrm{dt}$ during and after various forms of exercise in 70 normal subjects and 30 patients with ischaemic heart disease. This phase was divided into three different procedures to study the problems of recording $\mathrm{dZ} / \mathrm{dt}$ waveform during isometric hand grip exercise, dynamic bicycle ergometer exercise at varying workloads, and treadmill exercise. Fifty normal subjects were studied for the isometric hand grip series. Thirty patients with ischaemic heart disease and 20 normal subjects were studied before, during, and after dynamic exercise. The recording procedure for isometric exercise was identical to that in phases I and II. For dynamic exercise the following modifications were made.

(1) The electrocardiogram was obtained by using reusable floating column type of exercise electrodes in a bipolar configuration $\left(\mathrm{CM}_{5}\right)$ fixed to the skin as routinely done for exercise testing (Balasubramanian et al., 1975b).

(2) Phonocardiograms were obtained by using a pellet microphone (HM 692) ${ }^{1}$ fixed to the third left interspace by a twinsided adhesive disc.

(3) Disposable aluminium-coated mylar strip electrodes were used for impedance studies. ${ }^{2}$ The electrode/patient cable interface was snugly fixed by using adhesive plaster and elastic crepe bandage.

All studies were conducted in a temperature controlled laboratory kept at $26^{\circ} \pm 2{ }^{\circ} \mathrm{C}$.

The following measurements were made using five consecutive complexes to an accuracy of 5 milliseconds.

(1) Electromechanical systole $\left(Q-S_{2}\right)$.

(2) Left ventricular ejection time derived from the carotid pulse (LVET C $_{\mathrm{c}}$.

(3) RR interval and heart rate.

(4) Left ventricular ejection time derived from the impedance cardiogram $\left(\operatorname{LVET}_{\mathrm{z}}\right)$. The onset was at a point where the calibration line intersected the upslope and the end point was located at a clear dip ( $x$ point) synchronous or just after the first high frequency component of second sound.

(5) Pre-ejection period derived from the carotid pulse by the formula $\mathrm{QS}_{2}-\mathrm{LVET}_{\mathrm{c}}$.

\footnotetext{
1 Kombinat Veb Messegeratewerk, GDR.

${ }^{2} \mathrm{M} / \mathrm{s}$. Avionics Research Products, Palo Alto, California, USA.
}

(6) Pre-ejection period derived from the impedance cardiogram was measured directly from the onset of the initial depolarisation of the electrocardiogram to the intersection of the upslope of $\mathrm{dZ} / \mathrm{dt}$ and the baseline (Fig. 1).

The phase I graphs were analysed using the blinding method suggested by Quarry-Pigott et al. (1973) and the other graphs by two independent observers. The values in phases II and III were corrected by using the following regression equations (Lindquist et al., 1973):

LVET $=1.42 \mathrm{HR}+$ observed value; PEP $=$ $0.44 \mathrm{HR}+$ observed value.

Data were fed into an ICL 1904 computer and the statistical analysis performed by standard methods (paired t test, and linear regression analysis).

\section{Results}

\section{PHASE I}

The mean LVET $_{c}$ was $285.4 \pm 17.8 \mathrm{~ms}$ obtained from 250 complexes of 50 subjects. By comparison the LVET $_{z}$ was $285.6 \pm 17 \cdot 2 \mathrm{~ms}$. The mean heart rate during these recordings was $64 \cdot 2 \pm 9 \cdot 7 \mathrm{~min}$. The values were statistically identical and linear regression analysis showed a very close correlation $(r=0.976)$. The $\operatorname{PEP}_{z}$ obtained by direct measurement was $91.8 \pm 6.2 \mathrm{~ms}$. The PEP $\mathrm{P}_{\mathrm{c}}$ obtained indirectly was $92.7 \pm 7.2 \mathrm{~ms}$. Scanning the individual values showed that $\mathrm{LVET}_{\mathrm{z}}$ was identical with LVET $_{c}$ in 165 of 250 values, and within $10 \mathrm{~ms}$ in the rest.

In 7 subjects the carotid pulse was obtained after some difficulty and the optimal recommended amplitude of $30 \mathrm{~mm}$ could not be achieved even with full amplification. The $\mathrm{dZ} / \mathrm{dt}$ waveform posed no difficulties in recording or in obtaining the requisite amplitude. The ease of recognition of the end points was then analysed in 497 complexes. The dicrotic notch of the carotid was not clear in 38 of 497 complexes and the ' $\mathrm{X}$ ' point of $\mathrm{dZ} / \mathrm{dt}$ was not clear in 61 .

\section{PHASE II}

In this phase we obtained a total of 9 sets of recordings of 35 subjects yielding data from 3150 complexes ( 1575 carotid and $1575 \mathrm{dZ} / \mathrm{dt}$ ). The two sets of graphs were analysed by two independent observers unaware of each other's results and the values were corrected for heart rate by the regression equations used in our laboratory. The values are expressed in Table 1 . It was seen that the mean values were always within $5 \mathrm{~ms}$ of each other and a very close correlation ranging from 0.918 to 0.986 was observed on all the days. The uncorrected values ranged from $190 \mathrm{~ms}$ to $295 \mathrm{~ms}$ and the heart 
Table 1 Comparison of left ventricular ejection time obtained from carotid pulse and impedance cardiogram in 3150 complexes

\begin{tabular}{|c|c|c|c|c|}
\hline Study & $L V E T_{\mathrm{c}}$ & $L V E T_{\mathrm{z}}$ & $\boldsymbol{P}$ & $r$ \\
\hline Sea-level & $\begin{array}{c}380 \cdot 7 \\
(8 \cdot 8)\end{array}$ & $\begin{array}{l}379 \cdot 8 \\
(12 \cdot 5)\end{array}$ & NS & 0.962 \\
\hline \multicolumn{5}{|l|}{ High altitude } \\
\hline Day 1 & $\begin{array}{c}357 \cdot 1 \\
(10 \cdot 8)\end{array}$ & $\begin{array}{c}357 \cdot 1 \\
(12 \cdot 0)\end{array}$ & NS & 0.981 \\
\hline Day 2 & $\begin{array}{l}363.1 \\
(10.5)\end{array}$ & $\begin{array}{c}358 \cdot 3 \\
(9 \cdot 7)\end{array}$ & NS & 0.918 \\
\hline Day 3 & $\begin{array}{l}357 \cdot 4 \\
(11 \cdot 4)\end{array}$ & $\begin{array}{c}356.7 \\
(11.9)\end{array}$ & NS & 0.966 \\
\hline Day 4 & $\begin{array}{l}364 \cdot 8 \\
(11 \cdot 1)\end{array}$ & $\begin{array}{c}360.9 \\
(12.3)\end{array}$ & NS & 0.922 \\
\hline Day 5 & $\begin{array}{l}360.5 \\
(12.7)\end{array}$ & $\begin{array}{c}360.8 \\
(14.8)\end{array}$ & NS & 0.977 \\
\hline Day 10 & $\begin{array}{r}349 \cdot 9 \\
(9 \cdot 7)\end{array}$ & $\begin{array}{l}347 \cdot 0 \\
(11 \cdot 3)\end{array}$ & NS & 0.954 \\
\hline $\begin{array}{l}\text { Return to sea-level } \\
\text { Day } 2\end{array}$ & $\begin{array}{c}365 \cdot 8 \\
(9.6)\end{array}$ & $\begin{array}{c}368 \cdot 0 \\
(10 \cdot 5)\end{array}$ & NS & 0.928 \\
\hline Day 3 & $\begin{array}{c}372 \cdot 1 \\
(8 \cdot 6)\end{array}$ & $\begin{array}{r}371.8 \\
(9 \cdot 0)\end{array}$ & NS & 0.986 \\
\hline
\end{tabular}

LVET $_{c}$, left ventricular ejection period from carotid pulse; $\operatorname{LVET}_{\mathrm{z}}$, left ventricular ejection period from $\mathrm{dZ} / \mathrm{dt}$; NS, not significant; $r$, regression coefficient.

Figures in parentheses indicate standard deviation.

Table 2 Comparison of pre-ejection period obtained directly from impedance cardiogram and indirectly from carotid pulse in 3150 sets of recordings

\begin{tabular}{|c|c|c|c|c|}
\hline Study & $P E P_{\mathrm{c}}$ & $P E P_{\mathrm{z}}$ & $P$ & $r$ \\
\hline Sea-level & $\begin{array}{c}106 \cdot 8 \\
(9 \cdot 8)\end{array}$ & $\begin{array}{l}107 \cdot 6 \\
(11 \cdot 0)\end{array}$ & NS & 0.920 \\
\hline $\begin{array}{l}\text { High altitude } \\
\text { Day } 1\end{array}$ & $\begin{array}{r}111 \cdot 5 \\
(8 \cdot 5)\end{array}$ & $\begin{array}{l}114 \cdot 0 \\
(11 \cdot 6)\end{array}$ & NS & 0.901 \\
\hline Day 2 & $\begin{array}{l}115.9 \\
(10.0)\end{array}$ & $\begin{array}{l}118.0 \\
(14.6)\end{array}$ & NS & 0.911 \\
\hline Day 3 & $\begin{array}{l}115 \cdot 7 \\
(11 \cdot 3)\end{array}$ & $\begin{array}{l}118.0 \\
(14.6)\end{array}$ & NS & 0.914 \\
\hline Day 4 & $\begin{array}{l}116 \cdot 7 \\
(12 \cdot 6)\end{array}$ & $\begin{array}{l}120 \cdot 7 \\
(10 \cdot 7)\end{array}$ & NS & 0.909 \\
\hline Day 5 & $\begin{array}{c}119 \cdot 3 \\
(9 \cdot 2)\end{array}$ & $\begin{array}{l}122 \cdot 3 \\
(14 \cdot 0)\end{array}$ & NS & 0.910 \\
\hline Day 10 & $\begin{array}{r}120 \cdot 0 \\
(9 \cdot 8)\end{array}$ & $\begin{array}{l}123 \cdot 3 \\
(11 \cdot 3)\end{array}$ & NS & 0.907 \\
\hline $\begin{array}{l}\text { Return to sea-level } \\
\text { Day } 2\end{array}$ & $\begin{array}{c}118 \cdot 0 \\
(8 \cdot 3)\end{array}$ & $\begin{array}{l}121 \cdot 0 \\
(11 \cdot 1)\end{array}$ & NS & 0.910 \\
\hline Day 3 & $\begin{array}{l}111 \cdot 2 \\
(10 \cdot 5)\end{array}$ & $\begin{array}{l}114 \cdot 0 \\
(11 \cdot 6)\end{array}$ & NS & 0.903 \\
\hline
\end{tabular}

$\mathrm{PEP}_{\mathrm{c}}$, pre-ejection period obtained by the formula $\mathrm{QS}_{2}-\mathrm{VET}_{\mathrm{c}}$; $\mathrm{PEP}_{z}$, pre-ejection period obtained directly from the electrocardiogram and $\mathrm{dZ} / \mathrm{dt}$.

Other abbreviations as in Table 1.

rate varied from $45 / \mathrm{min}$ to $110 / \mathrm{min}$ under hypoxic stress. The individual values were within $\pm 10 \mathrm{~ms}$ of each other.

The $\mathrm{PEP}_{\mathrm{z}}$ and $\mathrm{PEP}_{\mathrm{c}}$ were not as closely related as in the phase I study (Table 2). This was attributed to certain alterations in impedance waveform occurring during hypoxic stress posing problems in exact identification of onset (Fig. 3). The correlation, however, ranged from 0.901 to 0.920 and the mean values were within $4.0 \mathrm{~ms}$ of each other. The individual values were within $10 \mathrm{~ms}$ of each other in all recordings.

\section{PHASE III}

Isometric handgrip exercise took two forms, i.e. maximal for 30 seconds and 30 per cent of maximal for 180 seconds. There were no gross alterations in the $\mathrm{dZ} / \mathrm{dt}$ waveforms and a stable graph could be obtained in all the 50 subjects. The onset and end points were not obscured by artefacts (Fig. 4). Dynamic exercise was administered by a constant load bicycle ergometer by increasing the workload by 25 WS every 3 minutes till fatigue supervened. The subjects pedalled at a speed of 50 to $60 \mathrm{rpm}$. Records were obtained in the sitting posture before exercise, at the end of each 3 minutes of exercise, at peak exercise with continued pedalling, and immediately after exercise, with pedalling stopped. Tracings were obtained at 10 minutes after stopping exercise in the sitting posture. The subjects were asked to hold their breath if possible during the recordings to obtain a stable baseline. Most of the subjects were able to do this for at least 5 to 10 seconds, which enabled adequate recordings in most of the cases.

Technically satisfactory recordings of electrocardiogram, phonocardiogram, and $\mathrm{dZ} / \mathrm{dt}$ were always obtained in the resting tracings and in those after exercise. Phonocardiograms were not clear in all the exercise recordings, thus rendering any measurement based on $S_{2}$ inaccurate. The $\mathrm{dZ} / \mathrm{dt}$ waveform was technically satisfactory up to 25 watts of exercise in all subjects, to 50 watts in 16 subjects, and to 100 watts in 6 . Increasing torso movement
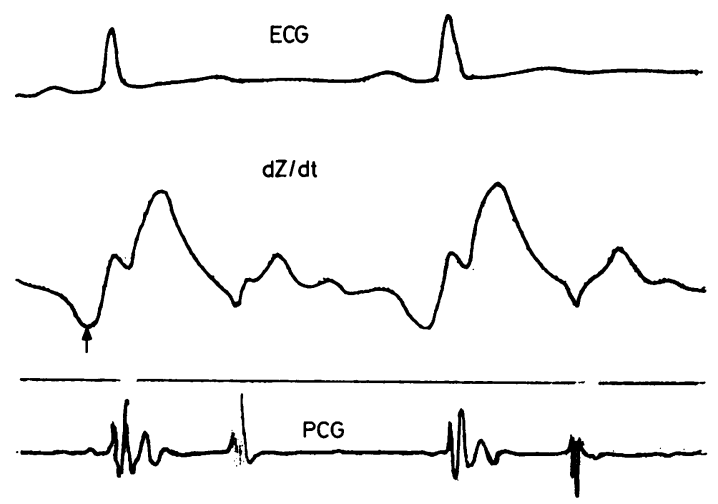

Fig. 3 The electrocardiogram, $d Z / d t$, and phonocardiogram of a healthy volunteer on the 4th day of stay at $3658 \mathrm{~m}$. There is a pronounced negative deflection with a small positive component before the main $d Z / d t$ waveform. This, when obvious, may render the direct measurement of PEP unreliable. (The figure has been retouched.) 

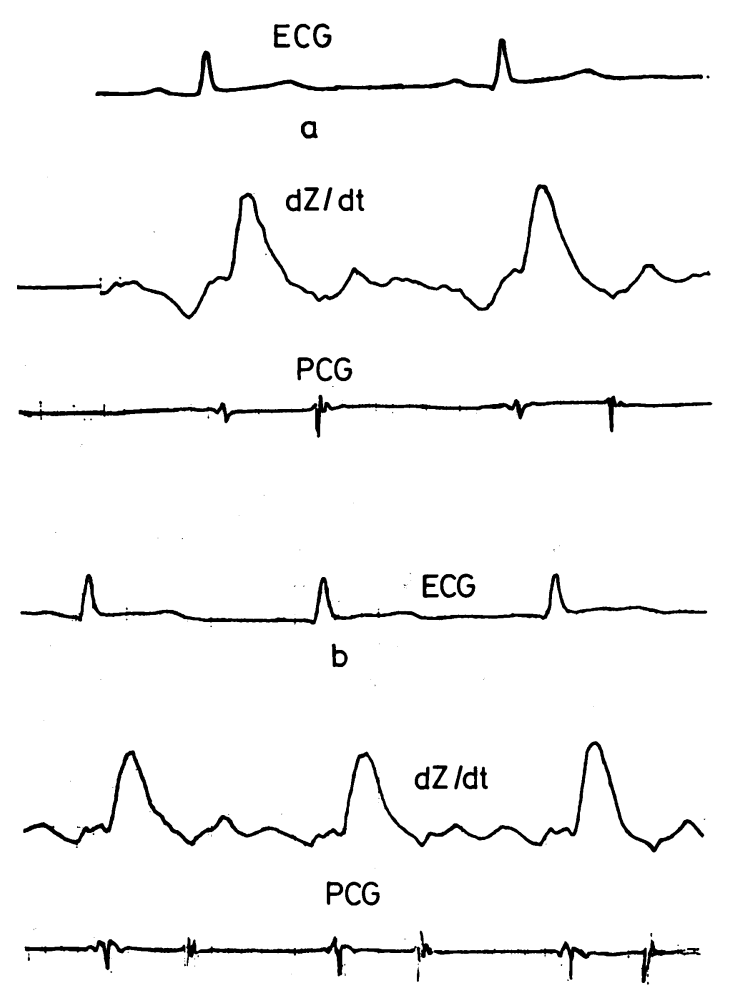

Fig. 4 The panel a shows $d Z / d t$ before isometric exercise and the panel $b$ at the peak of the static exercise. No deformation of the graph is observed.
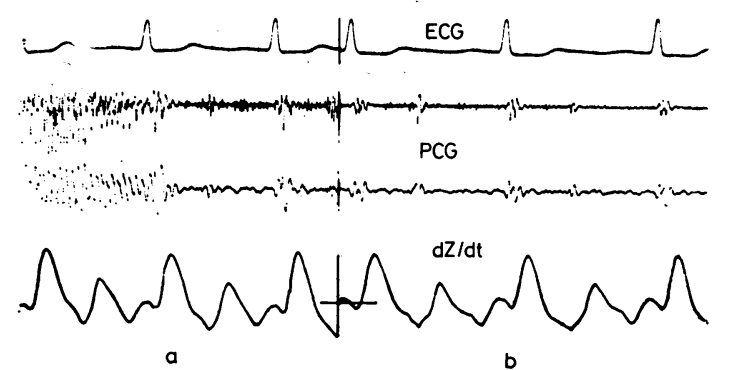

Fig. 5 Panel a shows the recording obtained at peak exercise. The phonocardiogram is not clear and $d Z / d t$ shows a mild baseline variation. Panel $b$ recorded immediately after exercise shows a disturbance-free recording ideal for calculations.

and electrode-patient cable interface movements at higher levels of exercise rendered the graph unstable and introduced artefacts. Technically satisfactory recordings could, however, be obtained in all patients at peak once pedalling was stopped. This was possible within 20 seconds in most cases. The onset and end-points were clearly discernible in all the technically satisfactory graphs. We could obtain proper measurements even up to heart rates of $190 /$ min. Fig. 5 shows the graphs obtained during exercise at peak during pedalling and immediately afterwards, with pedalling suspended. Table 3 shows the comparison of data from post-exercise impedance cardiograms and carotid pulse recordings.

Despite extreme care in electrode application and fixation satisfactory graphs could not be obtained during treadmill walking. Graphs were satisfactory once the walking was stopped and a recording could be obtained within 30 seconds of cessation of exercise.

\section{Discussion}

Noninvasive methods of assessing myocardial function are gradually becoming more popular because of their simplicity, reliability, and patient acceptance. Systolic time intervals as indirect measures of human cardiovascular performance have been extensively studied and correlated with a multitude of invasive techniques. As their value has now been firmly established, the attention of investigators is being focused on the development of newer, more accurate, and easily recordable noninvasive methods.

The electrical impedance cardiogram has been in clinical use for only about 20 years, as compared with the pulse recording techniques which were introduced as early as 1895 . The method has become viable after intense effort by a number of workers who refined and standardised the techniques (Kubicek et al., 1966, 1970, 1974; Van De Water et al., 1973; Hill and Lowe, 1973; Hill and Merrifield, 1976). The method is yet to find a place in any of the leading textbooks of cardiology or in

Table 3 Comparison of data obtained after isometric and dynamic exercise from impedance cardiograms and carotid pulse recordings

\begin{tabular}{|c|c|c|}
\hline & Isometric & Dynamic \\
\hline $\begin{array}{l}\text { Number of subjects } \\
\text { Number of complexes }\end{array}$ & $\begin{array}{r}50 \\
500\end{array}$ & $\begin{array}{r}50 \\
500\end{array}$ \\
\hline \multicolumn{3}{|l|}{ Technically satisfactory } \\
\hline $\begin{array}{l}\text {-impedance } \\
\text {-carotid }\end{array}$ & $\begin{array}{l}447 \\
460\end{array}$ & $\begin{array}{l}412 \\
345\end{array}$ \\
\hline Heart rate (maximal) & $109 \pm 8$ & $134 \pm 16$ \\
\hline LVET $_{c}$ & $\begin{array}{l}376 \cdot 6 \\
(12 \cdot 6)\end{array}$ & $\begin{array}{l}390 \cdot 0 \\
(14 \cdot 8)\end{array}$ \\
\hline $\operatorname{LVET}_{z}$ & $\begin{array}{l}374.8 \\
(11.8)\end{array}$ & $\begin{array}{c}386 \cdot 6 \\
(16 \cdot 6)\end{array}$ \\
\hline 'r' value & 0.964 & 0.951 \\
\hline $\mathbf{P E P}_{\mathrm{c}}$ & $\begin{array}{r}112 \cdot 4 \\
(6 \cdot 8)\end{array}$ & $\begin{array}{r}114 \cdot 6 \\
(6 \cdot 2)\end{array}$ \\
\hline PEP $_{z}$ & $113 \cdot 0$ & $116 \cdot 0$ \\
\hline ' $r$ ' value & $\begin{array}{l}(8 \cdot 0) \\
0.931\end{array}$ & $\begin{array}{l}(7 \cdot 0) \\
0.918\end{array}$ \\
\hline
\end{tabular}


the recent review articles or monographs on noninvasive techniques (Weissler et al., 1972; Hurst, 1974; Weissler, 1974; Zoneraich, 1974).

Geddes and Baker (1968) realised the potential of this method almost a decade ago. They said, 'the impedance method offers all the advantages of the indirect techniques used in the biomedical sciences, the most important being the integument need not be penetrated to make the measurements. Since electrodes are very easy to apply, practicality is an attractive feature of the method. Because a specialized transducer is not required, the same electrodes can be used to detect a variety of events in man and animals. In the absence of a transducer the response time is mainly governed by the event. If the electrodes are small enough they offer little restraint to the subject and need not modify the phenomenon under study. Unlike many transducers, electrodes are affected little by temperature and the barometric pressure changes. This property makes the impedance method practical for monitoring events under changing environmental conditions.'

This study was undertaken to explore thoroughly the scope and limitations of the impedance cardiogram as a measure of left ventricular ejection time in man. We conducted controlled studies under various types of stress such as high altitude hypoxia, and static and dynamic exercise. We find that the impedance cardiogram offers a suitable and versatile method for obtaining various systolic time intervals under resting conditions. It does not yield satisfactory results during dynamic exercise, particularly treadmill walking. The biggest problem faced during these recordings are movements at electrode-patient cable interface generating sharp spikes, and technical improvement in this aspect is needed.

In all other conditions both at rest and immediately after exercise we obtained good tracings which yielded values identical to those derived from carotid pulse recordings.

One of the limitations of this technique is the necessity for holding the breath in expiration in order to get satisfactory tracings. This may be difficult in extremely ill patients and during exercise. The use of a trace-stabilising circuit may offer a suitable method for obtaining satisfactory recordings in these situations. Occasionally the $\mathrm{X}$ point is difficult to identify, and in such situations the aortic closure of the phonocardiogram may be used as an end-point, the validity of which has been confirmed by Hill and Merrifield (1976).

The $\mathrm{dZ} / \mathrm{dt}$ waveform can be distorted in the presence of valvular regurgitation and intracardiac shunts. Occasionally the ascending limb of the $\mathrm{dZ} / \mathrm{dt}$ is deformed by a giant ' $\mathrm{a}$ ' wave (Fig. 3 ). This was seen mainly on high altitude induction. In such situations the inherent limitations of the impedance technique should be kept in mind.

The carotid pulse has been used conventionally for the derivation of left ventricular ejection time. It requires proper identification of the carotid artery, a transducer or a crystal microphone, and stable conditions for proper recording. Occasionally the onset and the dicrotic notch may not be clearly visible requiring the extension of the most vertical part of the curve for exact identification.

In our study of 50 subjects (phase I) the carotid pulse could be found only with difficulty in 7 of them and onset/end points were difficult to identify in 38 of 497 complexes. In the case of $\mathrm{dZ} / \mathrm{dt}$, the $\mathrm{X}$ point, if absent, could be identified from the aortic closure. No major discrepancy was noted in measurements of pre-ejection period and left ventricular ejection time by these two techniques, the values always being within $\pm 10 \mathrm{~ms}$ of each other, thus confirming the validity of the impedance technique in comparison with carotid pulse recordings.

The advantages of using the impedance cardiogram in preference to carotid pulse tracings for routine systolic time interval estimation are manifold. The event is a central pulse with negligible pulse transmission time. This enables direct measurement of pre-ejection period and permits cross-checking the time of aortic closure by location of the X point (Hill and Merrifield, 1976). There is no need to apply separate electrocardiographic electrodes as the impedance electrodes themselves pick up the electrocardiogram resulting in saving of time. The $\mathrm{dZ} / \mathrm{dt}$ waveform can be used to calculate stroke volume and two additional measures of myocardial function, i.e. the $R Z$ interval (distance between peak of $R$ wave of the electrocardiogram and peak of differentiated impedance cardiogram) and $\frac{\mathrm{dZ} / \mathrm{dt}}{\mathrm{RZ}}$ index (Hill and Merrifield, 1976; Siegal et al., 1970). The mean thoracic impedance values yield information about changes in intrathoracic fluid contents (Roy et al., 1974; Balasubramanian and Hoon, 1975; Balasubramanian and Hoon, 1976; Hoon et al., 1977).

The exact genesis of the thoracic impedance waveform has been a subject of controversy. Passage of a sinusoidal alternating current across the chest is associated with impedance changes which are synchronous with the cardiac cycle. The peak value of the first derivative of the impedance waveform was reported to have a linear relation to the peak flow in the ascending aorta as measured with an electromagnetic flowmeter in the dog. Furthermore, the second derivative of the 
impedance waveform was related to the first derivative of the aortic flow pattern suggesting that the former might be an index of blood acceleration in the aorta (Kubicek et al., 1967). Siegal and coworkers (1970) correlated thoracic impedance changes with aortic pressure pulse and found that the former was directly related to the ejected volume and the velocity of aortic flow. Geddes and Baker (1972) injected hypertonic saline in the canine right and left ventricle during thoracic impedance measurements and concluded that pulsatile impedance decrease was associated with cardiac activity, the major contribution being from the left ventricle.

Ito and coworkers (1976) investigated the source of the transthoracic impedance variations by perfusing the aorta and the pulmonary artery with a controlled sinusoidal or pulsatile flow. They concluded that the main component of the impedance waveform occurred as a result of pulsatile flow in the aorta rather than pulmonary blood flow.

The physiological correlates of the impedance waveform have been described in detail by a number of workers. Karnegis and Kubicek (1970) reported their experience in 58 patients, and noted that the amplitude of the $\mathrm{dZ} / \mathrm{dt}$ and brachial arterial pulse pressure were similarly affected by premature ventricular contractions. They concluded that the contraction of atria and of the ventricles were associated with identifiable components in the impedance waveform. Lababidi et al. (1970) described in detail the physiological correlates of the first derivative thoracic impedance cardiogram based on their experience in 91 subjects. They found certain points in $\mathrm{dZ} / \mathrm{dt}$ relating in time to the phonocardiogram and designated them $\mathrm{A}, \mathrm{B}, \mathrm{X}, \mathrm{Y}, \mathrm{O}$, and $\mathrm{Z}$. The A point coincided with the beginning of the fourth heart sound, the B point with the maximal vibrations of the first heart sound, the $\mathrm{X}$ point with aortic closure, the $\mathrm{Y}$ with pulmonary closure, the $O$ with the mitral opening snap, and $Z$ with the maximal vibration of the third heart sound. Rasmussen et al. (1975) found an excellent correlation $(r=0.986)$ between LVET measured from the aortic pressure curve and the $\mathrm{dZ} / \mathrm{dt}$ waveform in dogs. Hill and Merrifield (1976) compared left ventricular ejection time derived from carotid and impedance waveforms in 355 paired measurements and found a mean correlation of 0.952 .

The validity of using the crossing of the upstroke of the $\mathrm{dZ} / \mathrm{dt}$ waveform and the zero reference line as the onset of LVET requires clarification. Kubicek et al. (1970) advocated that the starting point for determining left ventricular ejection time should be obtained by going back in time down the $\mathrm{dZ} / \mathrm{dt}$ waveform from the negative peak to a point on the curve equal to $0.15 \times \frac{\mathrm{dZ}}{\mathrm{dt}}$. They felt that

the zero crossing of $\mathrm{dZ} / \mathrm{dt}$ before the peak could also be used, but because of occasional small oscillations in the waveform before the peak, $0.15(\mathrm{dZ} / \mathrm{dt})_{\max }$ is a more reliable point. Baker et al. (1971), however, advocated the zero crossing of $\mathrm{dZ} / \mathrm{dt}$. Rasmussen et al. (1975) found an excellent correlation between left ventricular ejection time measured from the central aortic pressure curve and impedance cardiogram using the zero crossing of the $\mathrm{dZ} / \mathrm{dt}$ as the onset. Denniston et al. (1976) also used the zero crossing of $\mathrm{dZ} / \mathrm{dt}$ for calculation of left ventricular ejection time. Hill and Merrifield (1976) used the crossing of the $\mathrm{dZ} / \mathrm{dt}$ waveform and the zero reference line as the point of onset to measure left ventricular ejection time. The experience of the majority of the workers was, therefore, adopted for this study.

In conclusion, this method appears to be ideal where long-term noninvasive monitoring of the systolic time intervals is required. There is no need to hand-hold any transducer and the electrodes can be left in situ for long periods ensuring repeated reliable recordings. This may prove valuable in the operating room, intensive care units, and for environmental studies, once the limitations are kept in mind and controlled.

This study was supported by the Armed Forces Medical Research Committee, India, under the projects, 636/74, 714/75, and 799/75. We are grateful to Director General, Armed Forces Medical Services, and Director, Medical Research, for financial assistance and permission to publish the paper. We acknowledge the assistance of Lt. Col. K. S. Chadrha, A.M.C., throughout the study.

\section{References}

Baker, L. E., Hill, D. W., and Pate, T. D. (1974). Comparison of several pulse pressure techniques for monitoring stroke volume. Medical and Biological Engineering, 12, 81-87.

Baker, L. E., Judy, W. V., Geddes, L. E., Langley, F. M., and Hill, D. W. (1971). The measurement of cardiac output by means of electrical impedance. Cardiovascular Research Centre Bulletin, 9, 135-145.

Balasubramanian, V., and Hoon, R. S. (1975). Applications of transthoracic electrical impedance-a non-invasive technique for detection of changes in thoracic fluid volumes. Fournal of the Association of Physicians of India, 23, 611-616.

Balasubramanian, V., and Hoon, R. S. (1976). Changes in transthoracic electrical impedance during submaximal treadmill exercise in patients with ischemic heart diseaseA preliminary report. American Heart fournal, 91, 43-49.

Balasubramanian, V., Kaushik, V. S., Manchanda, S. E., and Roy, S. B. (1975a). Effect of high altitude hypoxia on left ventricular systolic time intervals in man. British Heart fournal, 37, 272-276. 
Balasubramanian, V., Khanna, P. K., and Hoon, R. S. (1975b). On-line digital computer quantitated ST segment response to submaximal treadmill exercise. Fournal of the Association of Physicians of India, 23, 1-8.

Chirife, R., and Spodick, D. H. (1972). Densitography: a new method of evaluation of cardiac performance at rest and during exercise. American Heart fournal, 83, 493-503.

Denniston, J. C., Maher, J. T., Reeves, J. T., Cruz, J. C., Cymerman, A., and Grover, R. F. (1976). Measurement of cardiac output by electrical impedance at rest and during exercise. Fournal of Applied Physiology, 40, 91-95.

Geddes, L. A., and Baker, L. E. (1968). Principles of Applied Biomedical Instrumentation. John Wiley, New York.

Geddes, L. A., and Baker, L. E. (1972). Thoracic impedance changes following saline injections into right and left ventricles. Fournal of Applied Physiology, 33, 278-281.

Hill, D. W., and Lowe, H. J. (1973). The use of the electrical impedance technique for the monitoring of cardiac output and limb bloodflow during anaesthesia. Medical and Biological Engineering, 11, 534-545.

Hill, D. W., and Merrifield, A. J. (1976). Left ventricular ejection and the Heather index measured by non-invasive methods during postural changes in man. Acta Anaesthesiologica Scandinavica, 20, 313-320.

Hoon, R. S., Balasubramanian, V., Tiwari, S. C., Mathew, O. P., Behl, A., Sharma, S. C., and Chadha, K. S. (1977). Changes in transthoracic electrical impedance at high altitude. British Heart fournal, 39, 61-66.

Hurst, J. W. (1974). The Heart, Arteries and Veins, 3rd ed. McGraw Hill, New York.

Ito, H., Yamakoshi, K., and Yamada, A. (1976). Physiological and fluid-dynamic investigations of the transthoracic impedance plethysmography method for measuring cardiac output. Part II. Analysis of the transthoracic impedance wave by perfusing dogs. Medical and Biological Engineering, 14, 373-378.

Karnegis, J. N., and Kubicek, W. G. (1970). Physiological correlates of the cardiac thoracic impedance waveform. American Heart fournal, 79, 519-523.

Kubicek, W. G., Karnegis, J. N., Patterson, R. P., Witsoe, D. A., and Mattson, R. H. (1966). Development and evaluation of an impedance cardiac output system. Aerospace Medicine, 37, 1208-1212.

Kubicek, W. G., Kottke, F. J., Ramos, M. U., Patterson, R. P., Witsoe, D. A., Labree, J. W., Remple, W., Layman, T. E., Schoening, H., and Caramela, J. T. (1974). The Minnosota impedance cardiograph-Theory and applications. Biomedical Engineering, 9, 410-416.

Kubicek, W. G., Patterson, R. P., and Witsoe, D. A. (1970). Impedance cardiography as a non-invasive method of monitoring cardiac function and other parameters of the cardiovascular system. Annals of the New York Academy of Sciences, 170, 724-732.

Kubicek, W. G., Witsoe, D. A., Patterson, R. P., Mosharrafa, M. A., Karnegis, J. N., and From, A. H. L. (1967). Development and evaluation of an impedance cardiographic system to measure cardiac output and development of air oxygen consumption rate computing system utilizing a quadrupole mass spectrometer. NASA report NASA-
CR-92220. NASA, Washington, D.C.

Lababidi. Z., Ehmke, D. A., Durnin, R. E., Leaverton, P., and Lauer, R. M. (1970). The first derivative thoracic impedance cardiogram. Circulation, 41, 651-658.

Lindquist, V. A. Y., Spangler, R. D., and Blount, S. G., Jr. (1973). A comparison between the effects of dynamic and isometric exercise as evaluated by the systolic time intervals in normal man. American Heart fournal, 85, 227-236.

Martin, C. E., Shaver, J. A., Thompson, M. E., Reddy, P. S., and Leonard, J. J. (1971). Direct correlation of external systolic time intervals with internal indices of left ventricular function in man. Circulation, 44, 419-431.

Naggar, C. Z., Dobnik, D. B., Flessas, A. P., Kripke, B. J., and Ryan, T. J. (1975). Accuracy of the stroke index as determined by the transthoracic electrical impedance method. Anesthesiology, 42, 201-205.

Quarry-Pigott, V., Chirife, R., and Spodick, D. H. (1973). Ejection time by ear densitogram and its derivative; clinical and physiologic applications. Circulation, 48, 239-246.

Rasmussen, J. P., Sørensen, B., and Kann, T. (1975). Evaluation of impedance cardiography as a noninvasive means of measuring systolic time intervals and cardiac output. Acta Anaesthesiologica Scandinavica, 19, 210-218.

Roy, S. B., Balssubramanian, V., Khan, M. R., Kaushik, V. S., Manchanda, S. C., and Guha, S. K. (1974). Transthoracic electrical impedance in cases of high altitude hypoxia. British Medical fournal, 3, 771-775.

Siegal, J. H., Fabian, M., Lankau, C., Levine, M., Cole, A., and Nahmad, M. (1970). Clinical and experimental uses of thoracic impedance plethysmography in quantifying myocardial contractility. Surgery, 67, 907-917.

Spodick, D. H., and Lance, V. Q. (1976). Noninvasive stress testing. Methodology for elimination of the phonocardiogram. Circulation, 53, 673-676.

Van De Water, J. M., Mount, B. E., Barela, J. R., Schuster, R., and Leacock, F. S. (1973). Monitoring the chest with impedance. Chest, 64, 597-603.

Weissler, A. M. (1974). Noninvasive Cardiology. Grune and Stratton, New York and London.

Weissler, A. M., Harris, W. S., and Schoenfeld, C. D. (1968). Systolic time intervals in heart farlure in man. Circulation, 37, 149-159.

Weissler, A. M., Harris, W. S., and Schoenfeld, C. D. (1969). Bedside technics for the evaluation of ventricular function in man. American fournal of Cardiology, 23, 577-583.

Weissler, A. M., Lewis, R. P., and Leighton, R. F. (1972). The systolic time intervals as a measure of left ventricular performance in man. In Progress in Cardiology, pp. 155-183. Ed. by P. N. Yu and J. F. Goodwin. Lea and Febiger, Philadelphia.

Zoneraich, S. (1974). Noninvasive Methods in Cardiology. Charles C. Thomas, Springfield, Illinois.

Requests for reprints to $\mathrm{Dr}$ V. Balasubramanian, Department of Cardiology, Northwick Park Hospital and Clinical Research Centre, Watford Road, Harrow HA1 3UJ. 